\title{
ELUORESCENCE EMISSION SPECTRAL MEASUREMENTS FOR THE DETECTION OF OIL ON SHORE
}

\author{
Lee K. Balick \\ DOE Rernote Sensing Laboratory, Bechtel Nevada, Las Vegas, Nevada USA
}

John A. Di Benedetto and Stephen S. Lutz

DOE Special Technologies Laboratory, Bechtel Nevada, Santa Barbara, California USA .

\begin{abstract}
The U.S. DOE Special Technologies Laboratory is developing an airborne Laser-Induced Fluorescence Imaging (LIFI) system to support environmental management of government facilities. This system, or a system to be derived from it, is being evaluated for its potential to detect spilled oils on shore, in wetlands, and on ice. To more fully understand the detectivity of oil spills, emphasis has been placed on the spectral contrast between the oil signatures and signatures associated with the natural backgrounds (sand, vegetation, etc.). To support this evaluation, two series of controlled measurements have been performed to provide rigorous characterization of the excitation-emission properties of some oils and background materials, and to look at the effects of weathering of oil on terrestrial background materials. Oil targets included a heavy crude oil, diesel, kerosene, and aviation fuel and backgrounds included beach sand, straw, mud, tar and kelp. Fluorescence of oil on background materials decreases rapidly over the first few days of exposure to the environment and is more rapid than for neat oil samples.
\end{abstract}

\subsection{INTRODUCTION}

\subsection{PROJECT OBJECTIVES}

The long-term objective of this work is to develop laser-induced fluorescence imaging technology for the detection of spilled oil and oil products on shore, in wetlands, and on ice to support environmental remediation and monitoring. Laser-induced fluorescence is an appropriate technology for this problem because most oils and many refined products fluoresce in a spectrally distinct manner from the background material. Oils washed ashore often are confined to a long but very narrow zone, so a very high spatial resolution is necessary to map the zone. The Laser-Induced Fluorescence Imager (LIFI), being developed at the DOE Special Technologies Laboratory by Bechtel Nevada, has been chosen as a prototype system for this mission because of its spectral imaging capability and its high spatial resolution.

The LIFI is designed to image laser-stimulated fluorescence spectra with.a gated, microchannel-plate intensified camera in 128 spectral bands from the UV into the near IR. The laser illuminates a line perpendicular to the flight direction and an image is formed as the aircraft moves forward. Both active (fluorescence) and passive (reflectance) images can be obtained by imaging with and without the laser excitation. In its initial configuration, optimized for the detection of depleted uranium, the system is operated at low altitude on an Army Blackhawk helicopter with a $355 \mathrm{~nm}$ laser. Spatial resolution is about $10 \mathrm{~cm}$ by $25 \mathrm{~cm}$ with a swath about $50 \mathrm{~m}$ wide. Initial flight tests were scheduled for November 1996.

For presentation at the Fourth International Conference on Remote Sensing for Marine and Coastal Environments, Orlando, Florida, 17-19 March, 1997.

DISTRIBUTION OF THIS DOCUNENT IS UNLRITED

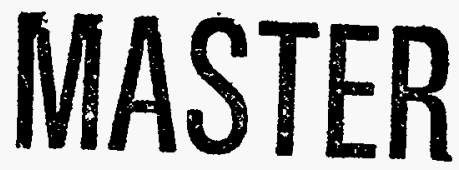

$$
\text { un }
$$




\section{DISCLAIMER}

Portions of this document may be illegible in electronic image products. Images are produced from the best available original document. 


\section{DISCLATMER}

This report was prepared as an account of work sponsored by an agency of the United States Government. Neither the United States Government nor any agency thereof, nor any of their employees, make any warranty, express or impliet, or assumes any legal liability or responsibility for the accuracy, completeness, or usefulness of any information, apparatus, product, or process disclosed, or represents that its use would not infringe privately owned rights. Reference herein to any specific commercial product, process, or service by trade name, trademark, manufacturer, or otherwise does not necessarily constitute or imply its endorsement, recommendation, or favoring by the United States Government or any agency thereof. The views and opinions of authors expressed herein do not necessarily state or reflect those of the United States Government or any agency thereof. 


\subsection{MEASUREMENT OBJĖCTIVES}

This paper reports an initial series of measurements needed in two areas. First, quantitative and detailed measurements of oil and background material fluorescence is required to model system performance to optimize the system for the detection of oil on shore. Secondly, knowledge of oil and background fluorescence in more realistic environments is needed. Specifically, information on oil fluorescence mixed with background materials and information on the temporal changes or weathering of oil fluorescence are needed. Oil on shore will mix with terrestrial materials and the fluorescence signature can be weakened or otherwise altered. For example, oil will seep into sand and only a thin layer may remain on top. A thin layer may weather faster than thicker layers, or the fluorescence spectrum of the background may be observed through the thin oil. The fluorescence signature will also change spectrally and with intensity over time as volatile components evaporate and surface properties change. The oil may also react with the background material causing changes in both components. Little information is available in the literature on these effects, so exploratory measurements on an outdoor laser range were initiated.

\subsection{MEASUREMENTS}

\subsection{EMISSION-EXCITATION MATRICES}

\subsubsection{Instrumentation and Procedures}

Fluorescence emission-excitation matrix (EEM) measurements were made using a SPEX Fluorlog fluorescence spectrophotometer. The instrument consists of a high pressure xenon light source, a double grating excitation monochrometer for selecting excitation wavelength, a sample chamber with provisions for 22 degree from surface viewing, a double grating emission monochrometer, a cooled photon-counting photomultiplier tube, and an interfaced computer for control and response correction.

We derived an emission correction curve for this instrument by recording the output from a NIST-traceable tungsten lamp illuminating a diffuse magnesium oxide surface in the sample chamber. The certified spectral distribution of the lamp output, in photons per nanometer, was divided point by point by the measured spectrum to obtain the correction curve that was subsequently used in all measurements. An excitation correction was made using a fluorescent cocktail consisting of a mixture of the coumarian-480 and DCM, dissolved in benzyl alcohol. This dye mixture was developed by this laboratory as a red emitting scintillation cocktail for fiber optic applications. It is very opaque throughout the visible with an optical extinction coefficient greater than $3.0 / \mathrm{mm}$. The emission maximum with front surface excitation is $630 \mathrm{~nm}$. These characteristics make it an excellent quantum counter for the correction of front-surface-excited fluorescence spectra, in the range 200 to $600 \mathrm{~nm}$.

Effective yield calibration is relative to the emission of di-phenyl-anthracene dissolved in cyclohexane, bubbled with nitrogen, and excited at $340 \mathrm{~nm}$, the peak of it absorption band. The yield numbers are defined as effective yield because we do not deal with the absorption in the excitation band of a given material. Effective yield, in this instance, is defined as the ratio of photons emitted to that of photons incident on a given material at a given excitation wavelength. All liquid measurements were made on $1 \mathrm{~cm}$. samples. Geometry constraints in the spectrometer limited the active area to less than $4 \mathrm{~mm}$ path length. The solids were all front surface illuminated. Spectra were taken at emission and excitation intervals of $5 \mathrm{~nm}$. 


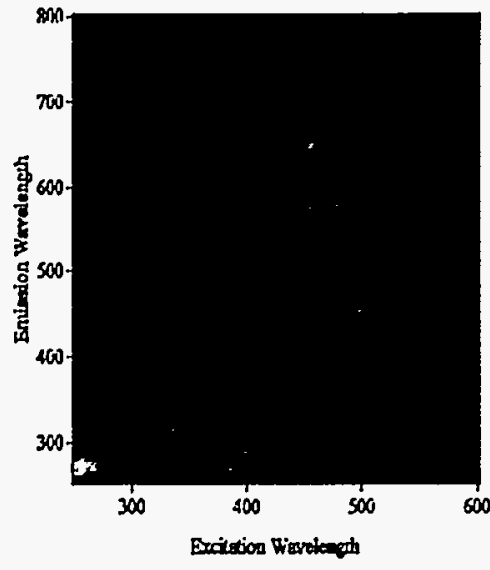

a) Avaition fuel

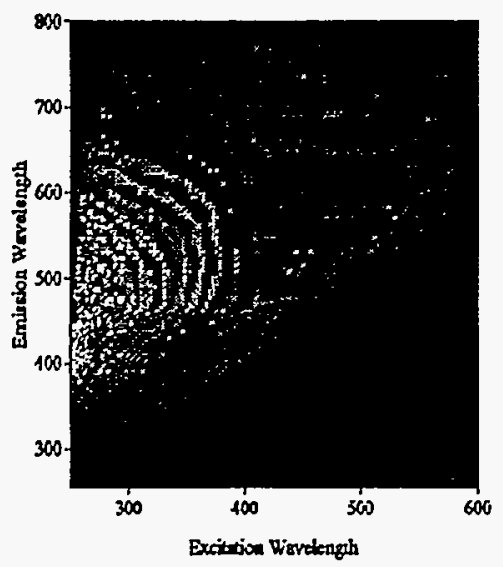

d) Heavy crude oil

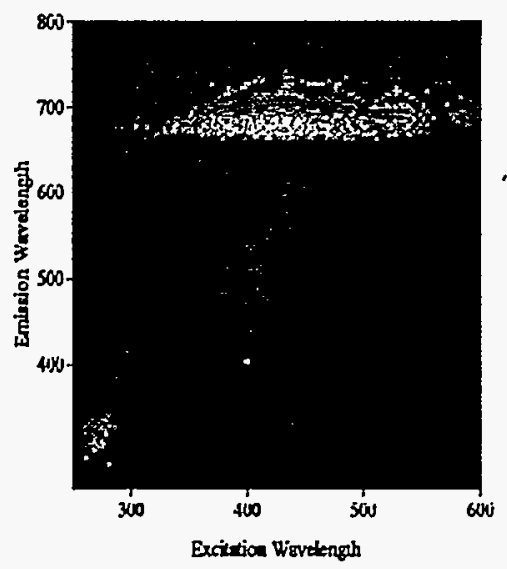

g) Kelp

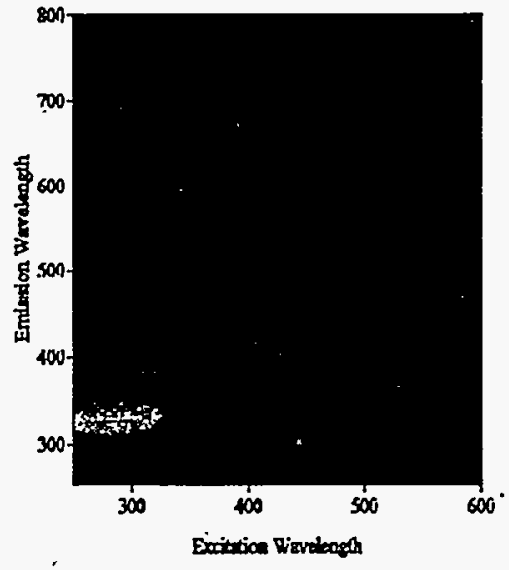

b) Kerosene

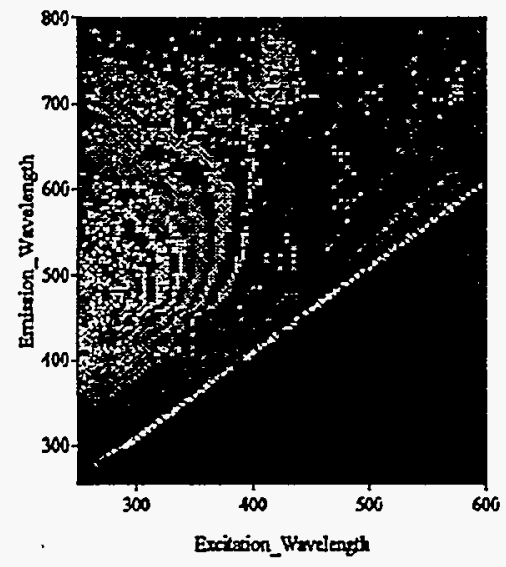

e) Beach tar

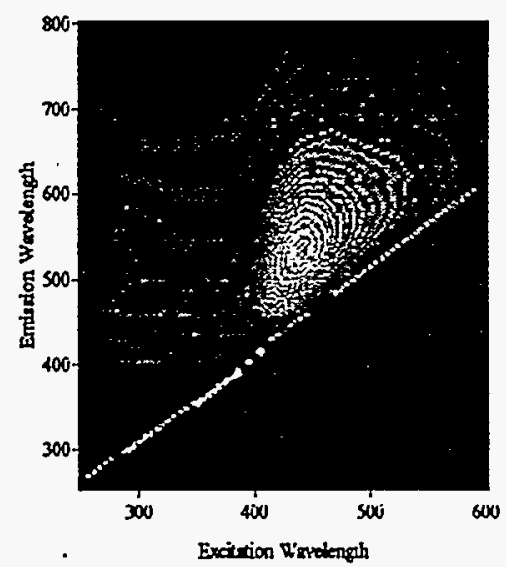

h) Senesced straw

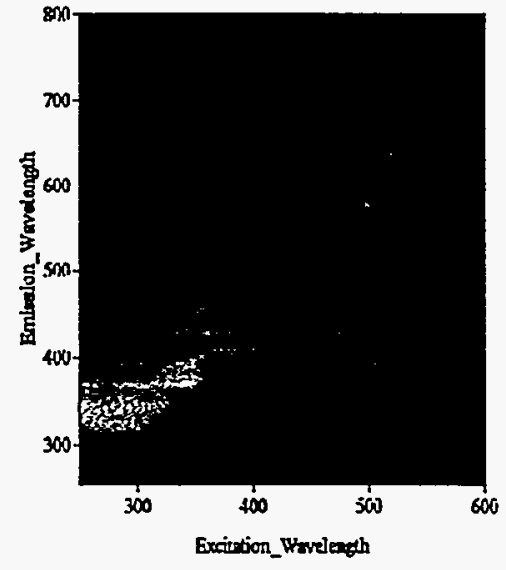

c) Diesel fuel

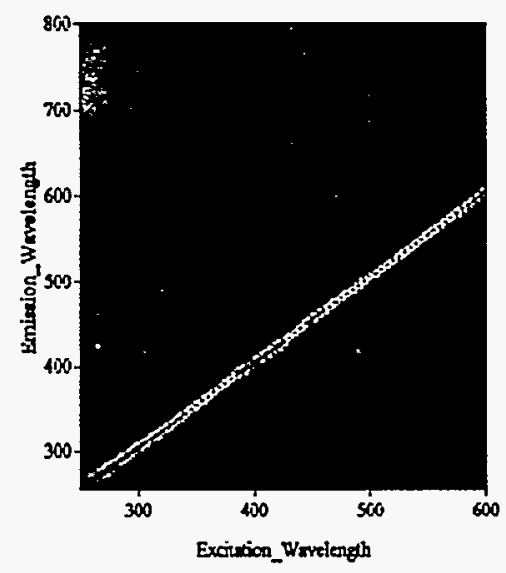

f) Beach sand

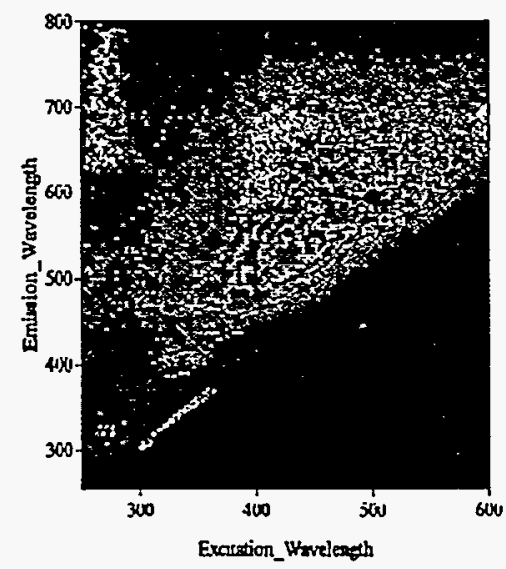

i) Wetlands muck

Figure 1. EEMs for Oils and Backgrounds. 
Oils were obtained from various local sources. The Santa Barbara Crude Oil was obtained from the Marine Spills Response Corporation and was considered to be a heavy crude and was fresh. The diesel was obtained from a gasoline service station pump and the kerosene was purchased from a home supply store. The aviation fuel was a commercial product obtained from a supplier at the Santa Barbara Airport. Background materials were also obtained locally. The sand was taken from the Goleta Beach above the high tide line (dry) as were the tar samples. Wetland mud was obtained from the banks of a tidal inlet near the airport. The straw was a senescent grass, leaves and stems cut into pieces about $5 \mathrm{~cm}$ long, obtained near the test area laser range. Kelp washed up on the Goleta Beach the previous night was also used for the measurements.

\subsubsection{Results}

EEMs were obtained for four oil types and five background materials. These data are presented in Figure la through Figure 1i. The data has been formatted as images with the emission wavelength along the $y$ axis, the excitation wavelength along the $x$-axis, and normalized intensity represented as a modulated grey scale. The peak of each spectra is represented as a white value for presentation.

The effective yield calibration puts this data into units of $\mathrm{nm}^{-1}$. If one then integrates along the emission axis, it is possible to plot total effective yield as a function of excitation wavelength. The results of this operation for the oils are shown in Figure 2. For the background materials, the results are shown in Figure 3. These graphs present the absolute effective (photons incident vs photons emitted) yield, summed across all visible emission bands, as a function of excitation wavelength.

Using the calibrated.EEMs, it is possible to calculate target-to-background fluorescent contrast as a function of emission and excitation wavelength. Target-to-background contrast is important, as it is the only possible discriminant for image mode detection. By performing contrast calculations using the scaled EEMs as inputs, it is possible to predict band ratios within a given scene. If one incorporates incident laser energy and detector performance into the calculation, it is possible to predict contrast signal-to-noise, and thus make statements about detection limits. However, the purposes of this paper, we shall only deal with target contrast. Figure 4 shows the results of a spectral contrast calculation between kerosene oil and kelp. As can be seen by the modulated grey scale presented at the bottom of the figure, the values vary from -1 to $1,-1$ representing a black target on a white background, 1 representing a white target on a black background. Both conditions are valid for target detection. As seen in this contrast plot, kelp fluorescence dominates in its red emission band. Kerosene fluorescence dominates in the 300 to $400 \mathrm{~nm}$ region. With multispectral detection, this contrast reversal is itself a signature that can be exploited.

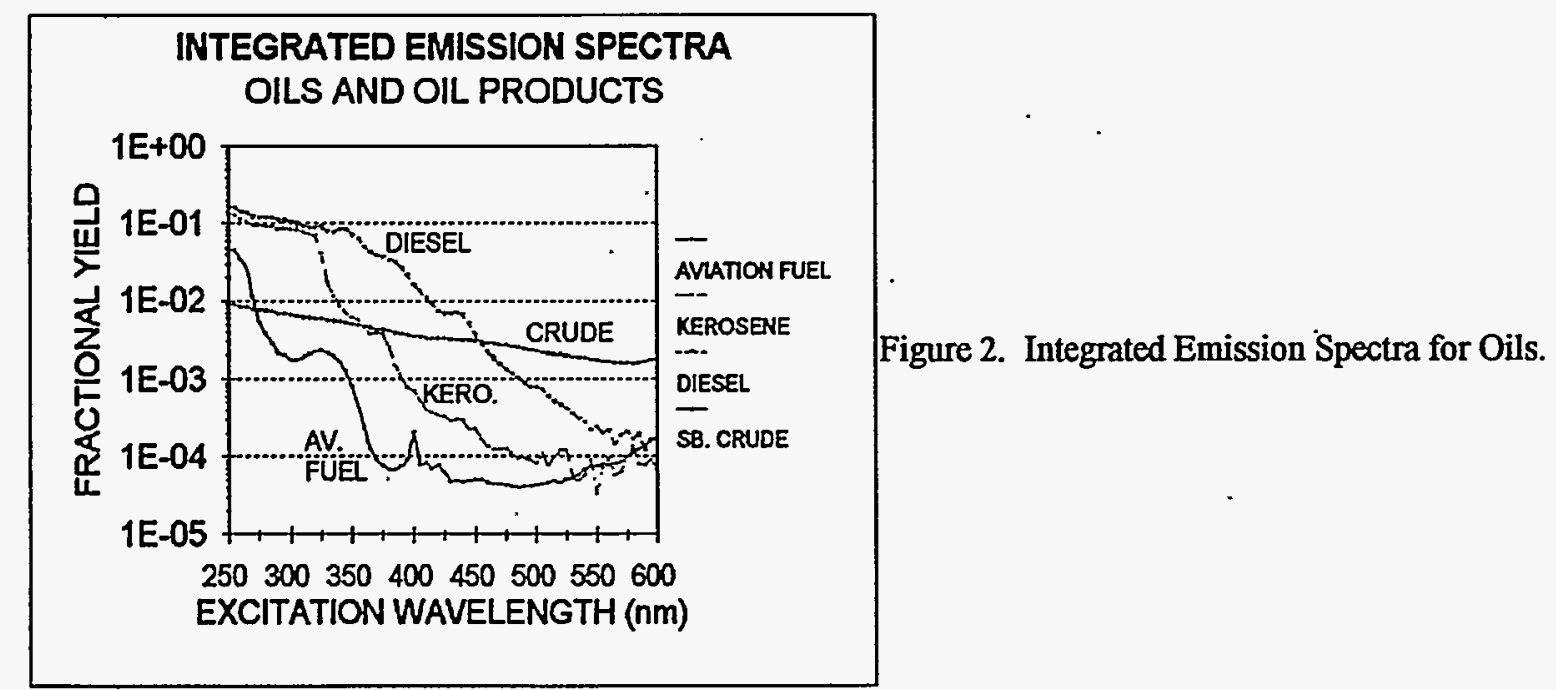



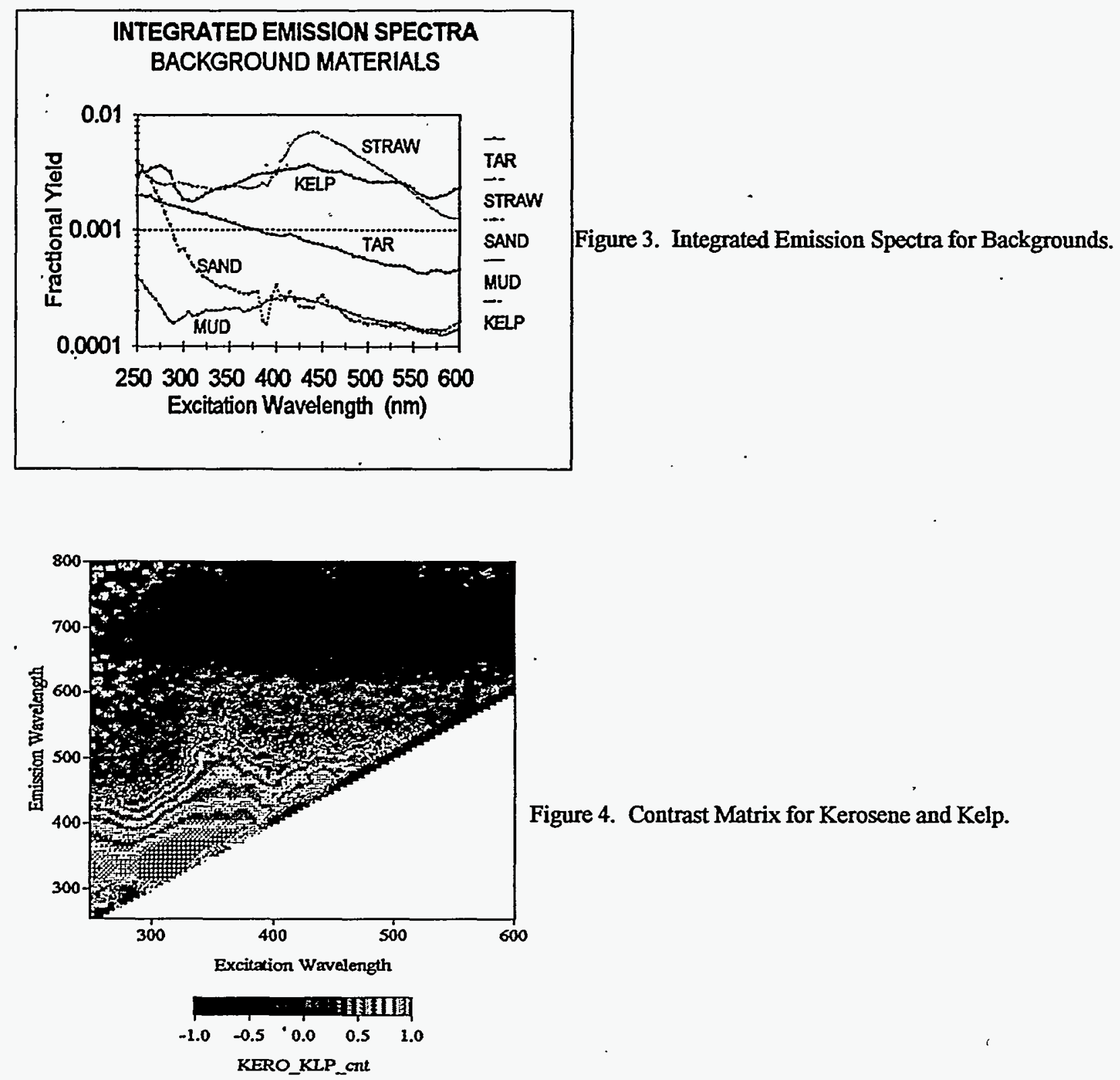

Figure 4. Contrast Matrix for Kerosene and Kelp.

\subsection{ENVIRONMENTAL EFFECTS}

\subsubsection{Instrumentation and Procedures}

An array of targets was illuminated with a $308 \mathrm{~nm}$ excimer laser and imaged with a 512 × 512 pixel micro-channel plate intensified CCD camera. Data were recorded digitally at 16-bit resolution. Data were taken at ten wavelength bands using dielectric filters covering the range from $340 \mathrm{~nm}$ through $400 \mathrm{~nm}$ at $20 \mathrm{~nm}$ increments (10 
$\mathrm{nm}$ band pass) and then from $450 \mathrm{~nm}$ through $700 \mathrm{~nm}$ at $50 \mathrm{~nm}$ increments ( $40 \mathrm{~nm}$ band pass). At each wavelength, a laser illuminated image was acquired, followed by a passive image. Later, the passive image would be subtracted from the laser image to eliminate the solar component from the daytime data and dark current subtraction. A large mirror above the targets enabled a perpendicular look on the horizontal targets from a distance of about $10 \mathrm{~m}$.

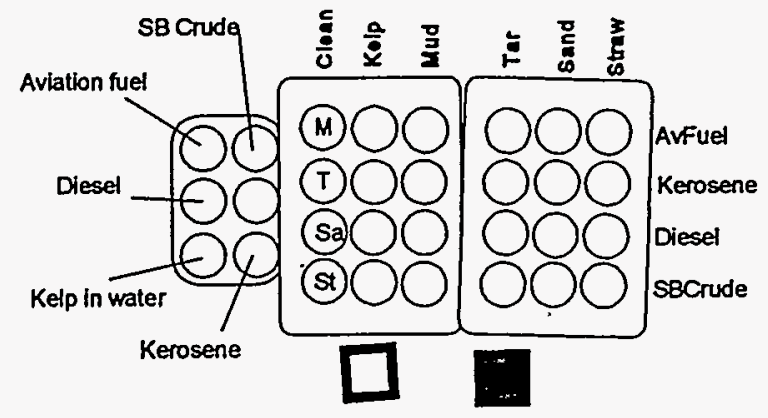

Figure 5a. Schematic of Target Array.

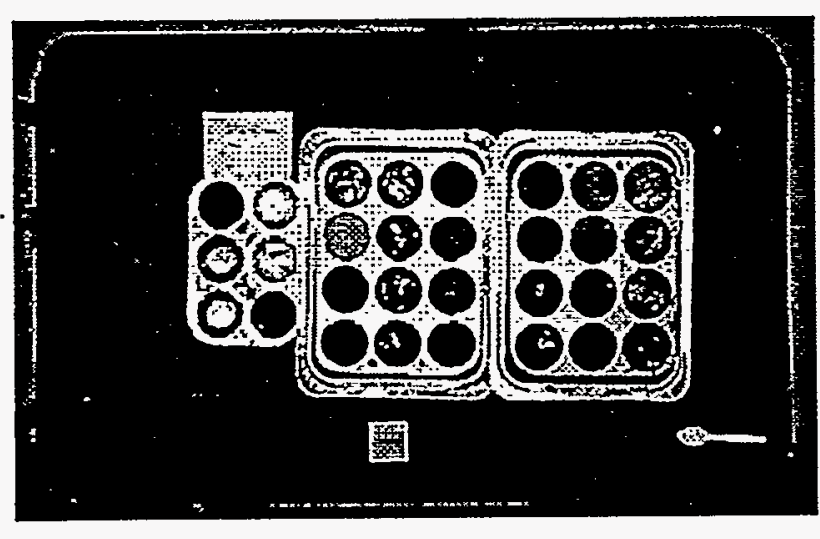

Figure 5b. Photograph of Target Array.

The target array consisted of neat samples of four oil types (Santa Barbara heavy crude oil, diesel oil, kerosene and aviation fuel, same types as for the EEMs) and neat samples of five background materials (straw or senescent grass, beach sand, tar, wetland mud, and a green kelp). Mixtures of each oil and each background material were prepared as follows. For the straw and sand, a sample of the material was soaked in the oil and then placed on an uncontaminated sample of the same material so the upper level could drain. For the tar and the wetland mud, 100 $\mathrm{ml}$ of the oil was slowly poured on the surface of the background material. Finally, leaf segments of the kelp were placed flat on a $100 \mathrm{ml}$ sample of each oil and allowed to float on top. A powdered gypsum target was placed in the scene as a reference standard to account for variations of laser output. A schematic diagram and a photograph of the target array is given in Figure $5 \mathrm{a}$ and $5 \mathrm{~b}$. The white square at the bottom is the gypsum reference and a dark square not visible in the photograph is an old oil target not used in this analysis. All images were multiplicatively normalized to the brightness of the gypsum reference in the first series of measurements, band by spectral band, after correction for the solar component and dark current. Mean values for each target were extracted from the gypsum-normalized image. Typically, $100-200$ pixels per target were used to determine the means. The spectral properties of targets must be considered as qualitative since adjustments were made for system spectral response: we are mostly interested in relative temporal and spectral changes. EEMs provide the definitive spectral characteristics of the materials.

\subsubsection{Results}

Nine sets of images, at ten wavelengths each, were acquired over a period of about 26 days. (The first seven of these were acquired in the first six days, then there was a gap, and the last two were acquired roughly 22 and 26 days from the start.) Discussion here is focused on the oils on the sand, straw and mud background materials and differences with neat samples. Oils partially dissolved the tar and kelp targets resulting in interesting spectral changes, but changes which are probably not highly representative of natural conditions.

Straw, sand, and mud backgrounds materials without oils were dark and steady over the observation period. Straw and sand showed a slight decrease of UV fluorescence over the first day or so, but the values are very low compared to most of the oils. Straw had a persistent peak at $500 \mathrm{~nm}$ to $550 \mathrm{~nm}$. 


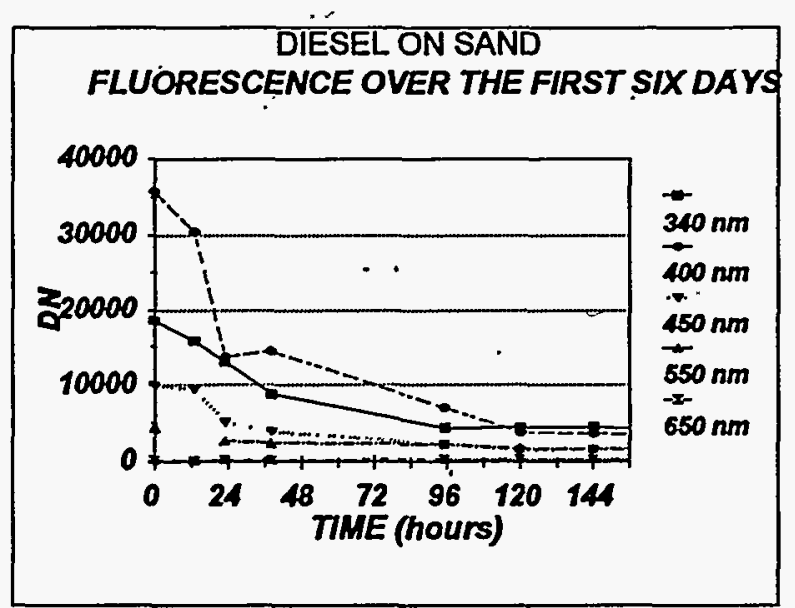

Figure 6. Diesel on Sand.

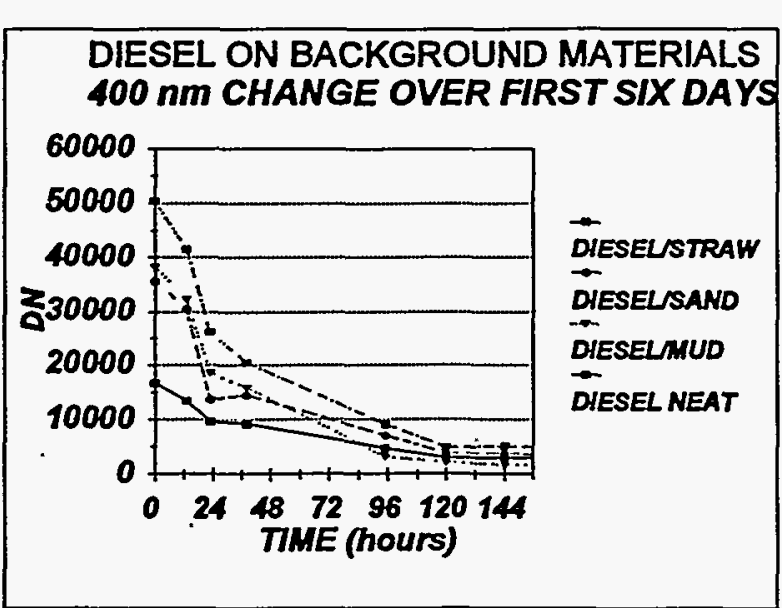

Figure 7. Diesel on Backgrounds (400 nm).

Diesel oil fluorescence underwent significant changes in time. Figure 6 shows the change of fluorescence for diesel on sand at five selected bands over the first six days and Figure 7 shows the change at $400 \mathrm{~nm}$. over the same period for diesel on different background materials. Over the first day, fluorescence decreases to roughly half of its original level. Fluorescence continues to decrease, but in the UV it is still significantly above background after 26 days. By the end of the measurements, fluorescence in the UV has decreased an order of magnitude. On straw, the data initially behave with similar trends but only with about one third of the brightness. By the fifth day, the 500 $\mathrm{nm} / 550 \mathrm{~nm}$ peak of the straw becomes visible in the data and is prominent afterward through the rest of the measurements. Also, the peak wavelength shifted weakly to shorter wavelengths: to $340 \mathrm{~nm}$ (reminder that the system is not spectrally calibrated) and is still significantly higher than background after 26 days. Fluorescence from diesel mixed with sand was initially darker than the neat sample but brighter than on straw. However, fluorescence decreased rapidly over time so that it was about half its initial value after two days. Between the second and the fourth day, decreases continued especially for the shorter wavelengths. Sometime during the measurement gap between the sixth and the 22 nd day, fluorescence in all channels was down to near background levels for the oil in sand.

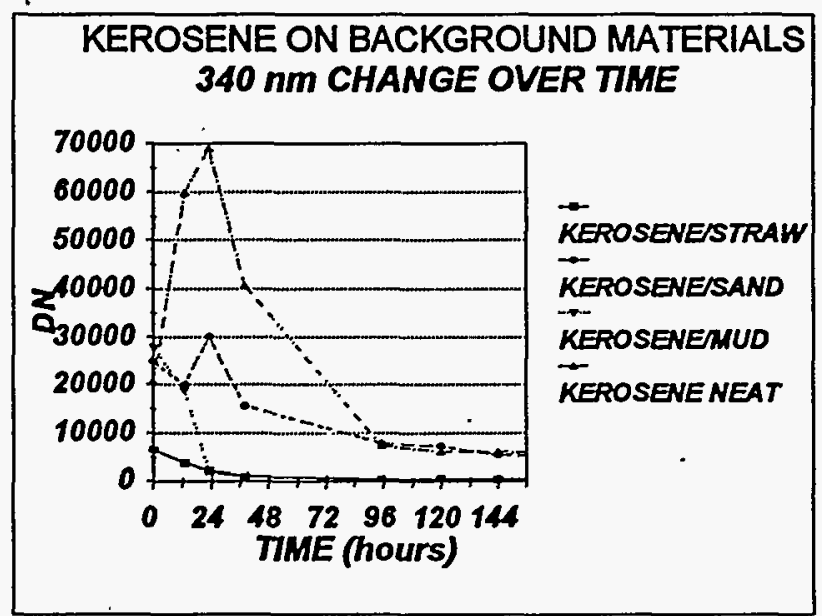

Figure 8. Kerosene on Backgrounds (340 nm).

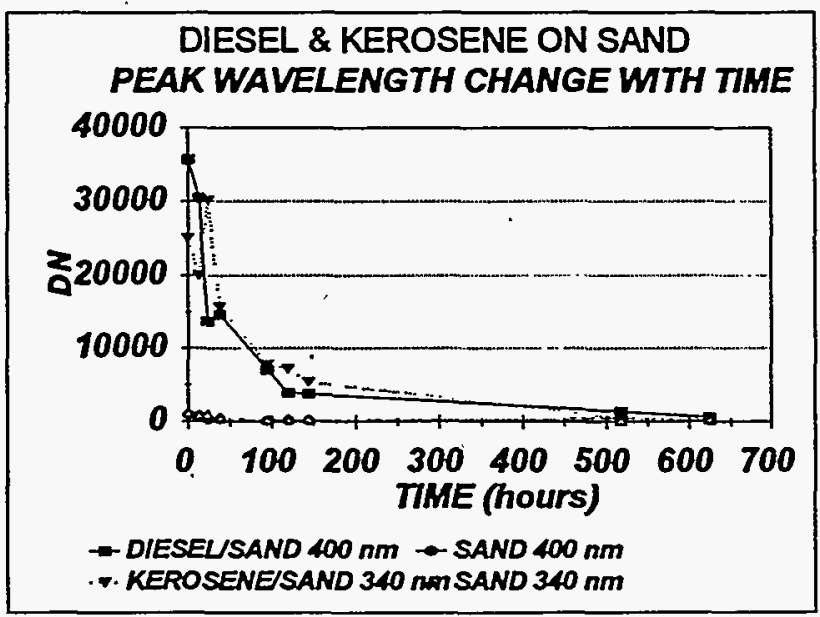

Figure 9. Diesel and Kerosene on Sand.

Kerosene fluorescence also goes through a large change over time. Figure 8 shows the change of fluorescence at 
$340 \mathrm{~nm}$ for neat kerosene and kerosene mixed with three background materials over the first six days. Initially kerosene is extremely bright at $340 \mathrm{~nm}$ falling off quickly with increasing wavelength. However, the change for the neat sample is a little more gradual than for diesel, or perhaps delayed about one day. On straw, however, kerosene is much darker than the neat sample and difficult to discern from the straw background after about one day. At one day, there is still a detectable fluorescence signature at $340 \mathrm{~nm}$, but it is gone by the second day and the target appears similar to uncontaminated straw. Kerosene on sand begins with a spectra that looks much like the neat sample but with a brightness between the neat sample and kerosene on straw. It is significantly above background, mainly in UV fluorescence, and like the neat sample, the UV fluorescence decay seems to be somewhat steadier than for diesel. Figure 9 shows a comparison of peak fluorescence of diesel (at $400 \mathrm{~nm}$ ) and kerosene (at $340 \mathrm{~nm}$ ) on sand over time: peak fluorescence is similar but they are spectrally distinct in the UV.

Santa Barbara crude oil had rather low fluorescence at all wavelengths. For the neat sample, UV fluorescence decreased the fastest, reaching a near steady state at a nearly undetectable magnitude by about three days. The highest fluorescence values were observed at $500 \mathrm{~nm}$. After two days, given the loss of $U V$ fluorescence and the persistence of a peak at $500 \mathrm{~nm}$, the neat sample of crude oil looked much like the neat straw sample.

Significantly, oil on straw was darker than either the neat oil or straw samples by a factor of about two. Like the neat oil sample, there was a loss of UV fluorescence over the first few days. A mixed crude-oil/straw target would be distinguished from a straw background mostly by being darker, and distinguished from a sand background by a peak in $500 \mathrm{~nm} / 550 \mathrm{~nm}$ fluorescence. Figure 10 shows that, at $550 \mathrm{~nm}$, crude oil on sand or straw are nearly the same but both are brighter than neat sand and darker than neat straw.

Aviation fuel mixed with backgrounds was rather dark at all wavelengths by the first measurement set. On sand, as shown in Figure 11, UV/blue fluorescence decreased leaving a residual peak at $500 \mathrm{~nm} / 550 \mathrm{~nm}$. It may be due to a blue dye added to the fuel and which remained behind as the fuel evaporated. Aviation fuel on straw was never discernable from straw, even in the first set of measurements. The $500 \mathrm{~nm} / 550 \mathrm{~nm}$ peak could not be discerned from the stronger peak at the same wavelength naturally in the straw. For the aviation fuel in sand, UV fluorescence was at best barely detectable and gone within the first day. However, the $500 \mathrm{~nm} / 550 \mathrm{~nm}$ peak was detectable immediately against the sand and persisted for the course of the measurements.

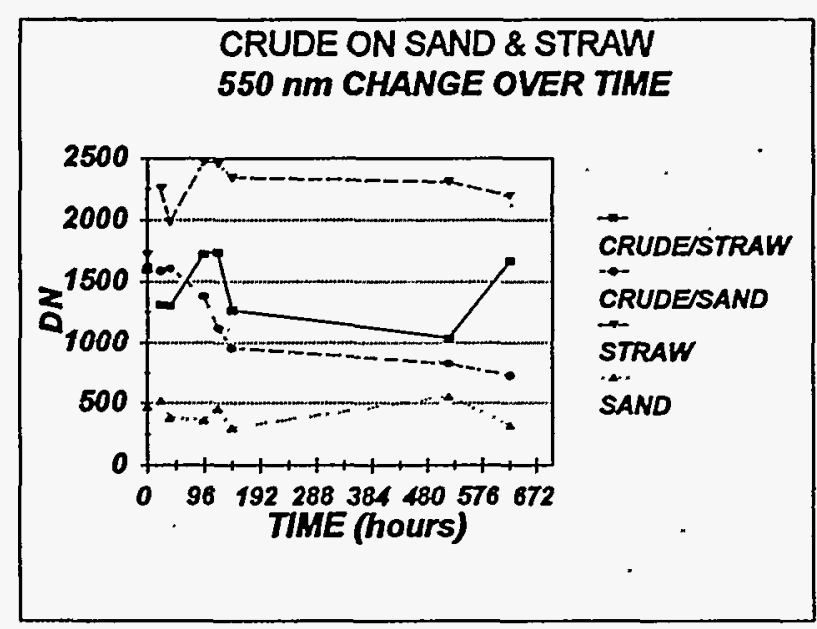

Figure 10. Crude Oil on Sand and Straw.

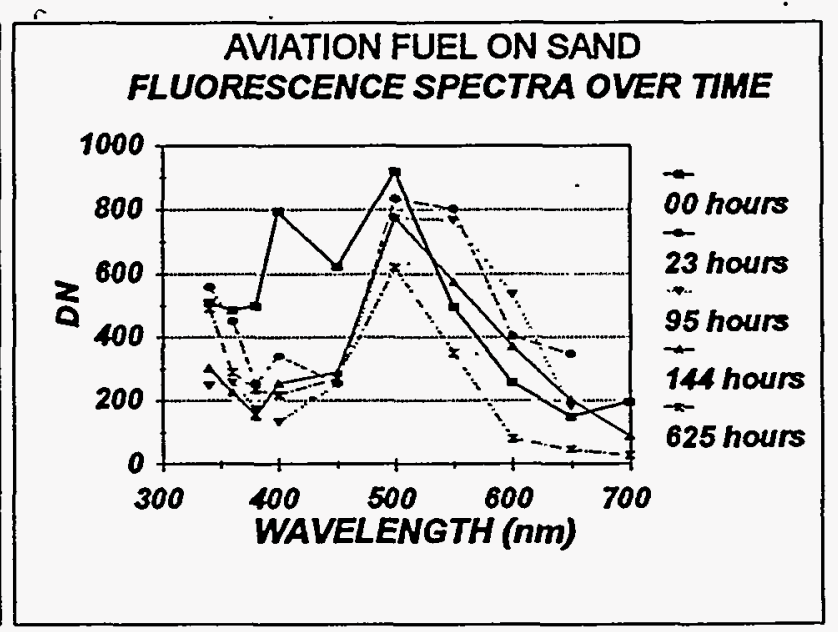

Figure 11. Aviation Fuel on Sand 


\subsection{CONCLUSIONS}

\subsection{EMISSION EXCITATION MATRICES}

Generally, the fluorescence characteristics of oils are distinct from the background materials tested. One exception is a low contrast between the heavy Santa Barbara crude oil and straw. While they were measurably distinct in the UV, contrast was low enough that it may be difficult to detect with noisy optical systems. The ultimate value of the EEMs is in optimizing the system for the targets and backgrounds of interest and to provide real, quantitative inputs to models which can then be used to judge the detectability of oil on shore as a function of system characteristics. It must be noted that only one sample per oil type was examined: we have not yet addressed the variability of fluorescence efficiency and spectra within oil type (the variability of diesel oils, for example). Clearly, a wider variety of oil types needs to be measured, especially for crude oils where the fluorescence can sometimes be weak.

\subsection{ENVIRONMENTAL EFFECTS}

\subsubsection{Mixtures}

The fluorescence of oils mixed with background materials was always considerably lower than the neat samples, even while fresh. The magnitude of the decrease was variable, but on the order of $50 \%$ (33\% to $66 \%$ is a fair range). The weakening of fluorescence over time seems to be due in part to oils soaking into the materials leaving only a thin film on the surface. This also accounts for the fact that fluorescence decreases faster when mixed with background materials, at least initially. Also, we hypothesize that the straw was darkest because its loosely compacted arrangement allowed for reabsorption of the fluorescence by neighboring target components. When the oil fluorescence weakens, background spectral features become visible in the data. This affected the detectability of the heavy crude oil (and the aviation fuel dye) against the straw background. It is concluded that the fluorescence signal from oils mixed with background materials are significantly less than the neat oils and that the spectra of the background materials can affect the observations when the oil fluorescence is weak.

\subsubsection{Weathering}

Fluorescence in the UV for all oils decreases rapidly after exposure to the air. Weathering effects are faster and often more pronounced for oils mixed with background materials. This result is consistent with Alaruri et al. (1995) who examined the effects of weathering of oils on water. They observed rapid and persistent decrease of fluorescence over several days, especially for thin films. For crude oil, the magnitude was not large but the fluorescence was low in the beginning. Diesel and kerosene UV fluorescence decreases an order of magnitude or so in a few days but still seems to be detectable against the dark, natural backgrounds. After about three weeks, however, detection seems problematic. Fluorescence in the visible part of the spectrum from dyes and non-volatile components of oils seem detectable for long periods of time, but may be obscured by the spectral features of the background material (e. g. straw). More detailed investigations are needed to understand the effects of various environmental factors on the temporal changes of fluorescence. Also, more detailed spectrographic or chemical analysis is needed to understand the chemical changes taking place that result in these temporal changes. The effects of differing environmental conditions on weathering, such as temperature and insolation, and the subsequent change of fluorescence still needs to be examined.

\subsection{ACKNOWLEDGMENT}

The Remote Sensing and Geographic Information System Center (RSGISC) of the U. S. Army Corps of Engineers supported this research under its Oil Spill Research Program funded under OPA 90. The program research, under 
the direction of Dr. Ike McKim, is managed by Major Bruce Gwilliam and is evaluated by Dr. Robert Bolus, all of the RSGISC. Work was supported by the U.S. Department of Energy Nevada Operations Office under Contract No. DE-AC08-96NV11718. By acceptance of this article, the publisher and/or recipient acknowledges the U.S. Government's right to retain a nonexclusive, royalty-free license in and to any copyright covering the article.

\subsection{REFERENCES}

Alaruri, S. D., M. Rasas, O. Alamedine, S. Jublan, F. Al-Bahrani, and M. Quinn, "Remote Characterization of Crude and Refined Oils Using a Laser Fluorosensor System, " Optical Engineering, Vol. 34, No. 1, pp. 214-221, January, 1995. 